\title{
Effect of Orifice Plate Shape on Performance Characteristics
}

\author{
Akshay Dandwate ${ }^{1}$, Sagar Mittal ${ }^{2}$, Oshin Umale ${ }^{3}$, Pallavi Shelar ${ }^{4}$, Rahul Bajaj $^{5}$ \\ Department of Mechanical Engineering \\ ${ }^{1,2,3,4}$ UG Students, Indira College of Engineering and Management, Pune. \\ ${ }^{5}$ Assistant Professor, Indira College of Engineering and Management, Pune.
}

\begin{abstract}
Flow measurement is measurement of the quantity of the fluid that passes through the pipe, duct or an open channel. Flow may be measured by measuring the velocity of fluid over a known area. Differential pressure measuring devices such as orifice plates and nozzles are extensively applied in several industries to estimate the mass flow rate running through a channel by correlating the measured pressure loss. In this paper, orifice plates with different geometry were designed and compared on the basis of their coefficient of discharge. This was done with the help of simulations done with $k-\varepsilon$ and SST model on CFX as a solver. Simulations were carried out on a single hole, perforated (5 holes, 7 holes and 9 holes) and triangular shape orifice plates. $\beta$ ratio taken was 0.6 for single hole, perforated, triangular orifice plates. By comparing the Cd. of various orifice plates, 7 holes orifice plate was found to be the best plate. This plate was manufactured and again tested experimentally. The result and outcomes are shown in the form of pressure contour, velocity contours and graphs showing comparison of $C_{d}$.
\end{abstract}

Keywords: Coefficient of discharge, CFD, Orifice plate, Boundary conditions, geometry.

\section{Introduction}

Flow measurement is the determination of the quantity of the fluid that passes through the pipe, duct or an open channel. Flow can be measured by measuring the velocity of fluid over a known area. The accurate measurement of a fluid is important to obtain specific proportions as per process requirements. It is important to maintain a definite flow rate for maximum efficiency and production. Without accurate measurements precise quality control is impossible. Flow measuring instruments are Venturimeter, Orifice Plate, Rota meter, Pitot tube, Flow Nozzles, etc. Out of these orifice meter is having least coefficient of discharge. The performance of orifice meter can be increased by changing shape of plate.

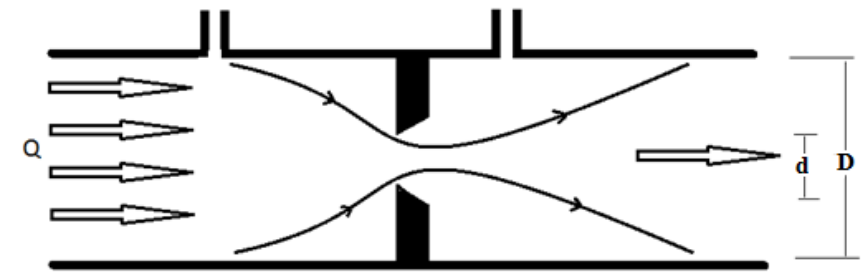

Figure 1: Orifice Meter

An orifice plate is a plate with a hole in it which is used to determine the flow rate of flowing fluid. As fluid passes through the orifice the pressure increases at the upstream of the orifice and the fluid is forced to pass through the hole. Due to obstruction, the velocity increases and the pressure decreases. At downstream, flow reaches at point where velocity is maximum and pressure is minimum and this section is known as vena contracta.

Yogesh Kumar et al. did the analysis on standard sharp edge orifice meter for different plate thicknesses $(3 \mathrm{~mm}, 5 \mathrm{~mm}, 10 \mathrm{~mm}$ and $15 \mathrm{~mm}$ ) in a pipe of $50 \mathrm{~mm}$ diameter and the effect of pipe diameter on coefficient of discharge has been studied. The value of coefficient of discharge depends on the type of flow, pressure tapping's, contour of the obstruction and it is a function of Reynolds number.

G. S. Karthik et al. did the analysis on standard sharp edge orifice meter for different plate thicknesses in a pipe of $50 \mathrm{~mm}$ diameter and the effect of pipe diameter on coefficient of discharge has been studied. From the work it has been shown that if the pipe diameter is decreased below $50 \mathrm{~mm}$ the value of Cd increases.

Mohamed A. Siba et al. studied the solution of unsteady and incompressible fluid was sought using a circular orifice as a function of three aspect ratios of 0.2, 0.4, and 0.6 taken at Reynolds number of 10000, 20000 , and 30000 . The study includes the velocity profile, the differential pressure, and the mechanical properties.

T. Sridevi et al. Flow analysis has been done on different types of flow meter using FLUENT solver and provision of track vena contracta has been explained. 
Malatesh Barki et al. presents the effect of orifice holes arrangement or distribution in a plate on the performance of flow characteristics. The analysis is carried out for four diameter ratio. The pressure drop is minimum for multi holes orifice plate compare to single hole. It shows that the nine holes in circular arrangement has better performance compare with square arrangement.

F. Saltara et al. evaluate the coefficient of discharge of orifice plate and long radius nozzles with diameters ratio 0:50 in the Reynolds range 15,000 - 5,00,000.using finite-volume based commercial code FLUENT. Incompressible steady-state analyses are conducted in three-dimensional domains discretized with unstructured meshes.

F. H. J. Imada et al. studied the simulated $\mathrm{C}_{\mathrm{d}}$ of orifice plates was over-estimated by both formulations with the k- $\omega$ model showing slightly better agreement. The predominance of viscous effects in the pressure drop through the nozzles was satisfactory captured with the two turbulence models, presenting underestimated results of $\mathrm{C}_{\mathrm{d}}$ within a $1 \%$ margin from the ISO Standard expected values.

\section{Experimentation}

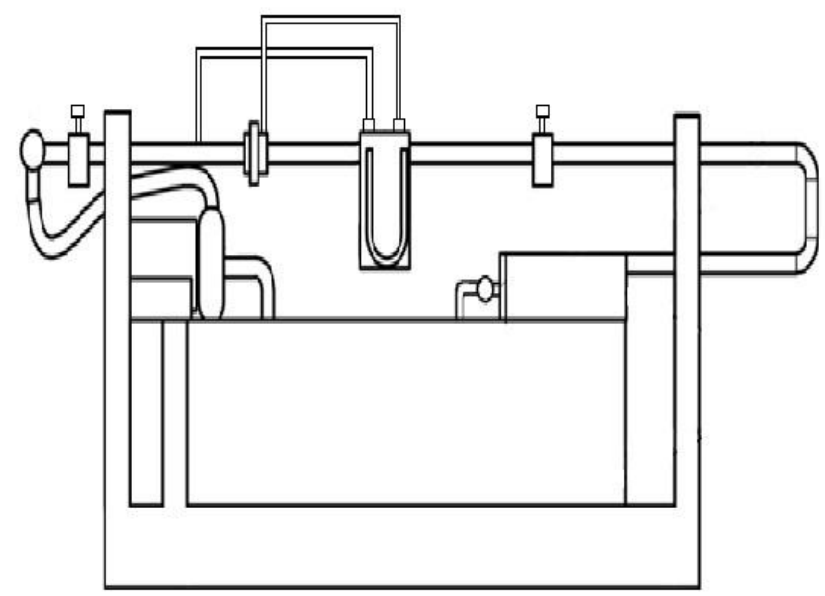

Figure 2: Orifice Meter Test Rig

Using a physical model, i.e. a test rig of orifice meter, observations in the form of pressure at inlet and outlet tapings, pressure drop and time for rise of water level in collecting tank are taken to calculate actual and theoretical discharge by varying discharge at inlet. These two discharge are used to calculate coefficient of discharge.

The discharge coefficient is the ratio of the actual discharge to the theoretical discharge.

$$
\mathrm{C}_{\mathrm{d}}=\frac{\text { Actual discharge }}{\text { Theoritical discharge }}
$$

\section{A. Geometric Modeling}

In the present work, for the study of orifice meter, the domain from the inlet to outlet of pipe having orifice plate was created. The orifice plate was modeled for single, perforated (5, 7 and 9 holes) and triangular hole. The modeling has been done in ICEM CFD. The total length of pipe was taken as $300 \mathrm{~mm}$ and pipe diameter was $25 \mathrm{~mm}$. The upstream length was $5 \mathrm{D}$ and downstream was 7D, where $\mathrm{D}$ is the diameter of pipe. The diameter of hole for single, 5, 7 and 9 hole orifice plate was taken as $15 \mathrm{~mm}, 6.7 \mathrm{~mm}, 5.6 \mathrm{~mm}$ and $5 \mathrm{~mm}$ respectively. The length of each side for the triangular hole was taken as $20 \mathrm{~mm}$. The area of hole was kept constant in all the plates.

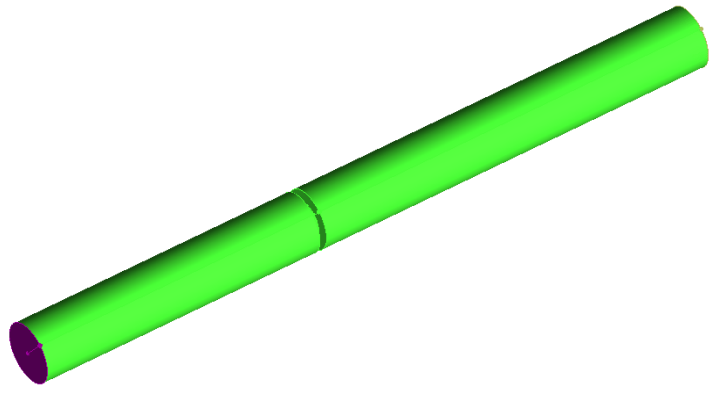

Figure 3: Geometrical modeling of Orifice Pipe 


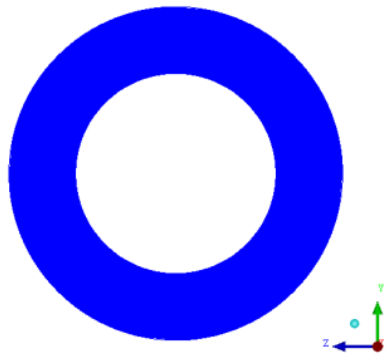

Figure 4: Single Hole Orifice Plate

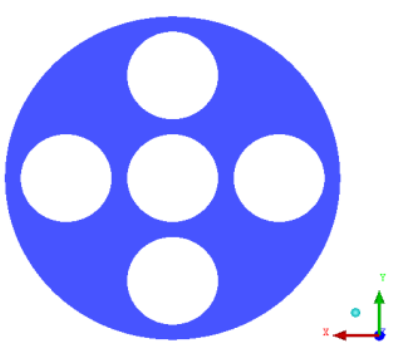

Figure 5: 5 Hole Orifice Plate

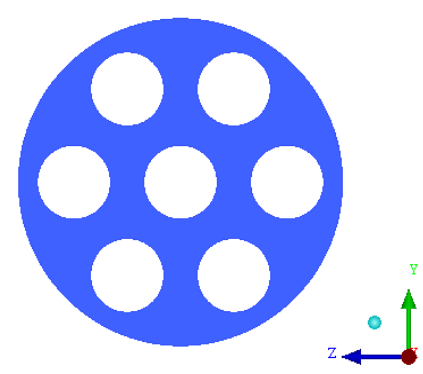

Figure 6: 7 Hole Orifice Plate

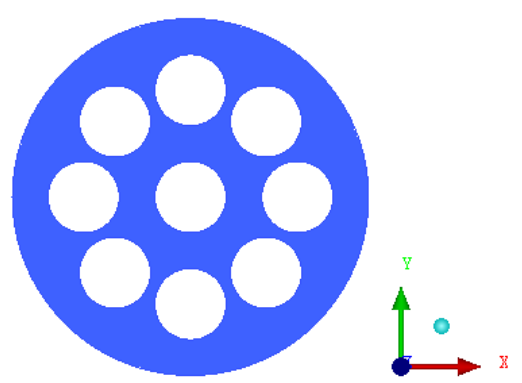

Figure 7: 9 Hole Orifice Plate

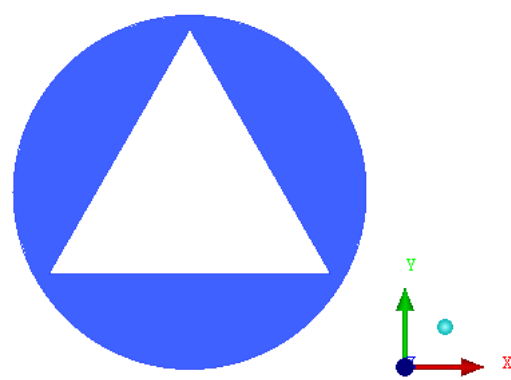

Figure 8: Triangular Hole Orifice Plate 


\section{Mesh Generation}

In numerical simulation, type of mesh, size of mesh and its quality affects the accuracy of results. The domain is discretised into tetrahedral elements. Mesh type is tetra mixed and mesh method is robust octree. The mesh for the pipe is shown in fig. 9. The total number of elements were 280480 and total nodes were 48342 . At BODY total number of elements were 262564. At INLET total number of elements were 324. At OUTLET total number of elements were 333. At WALL total number of elements were 17259.

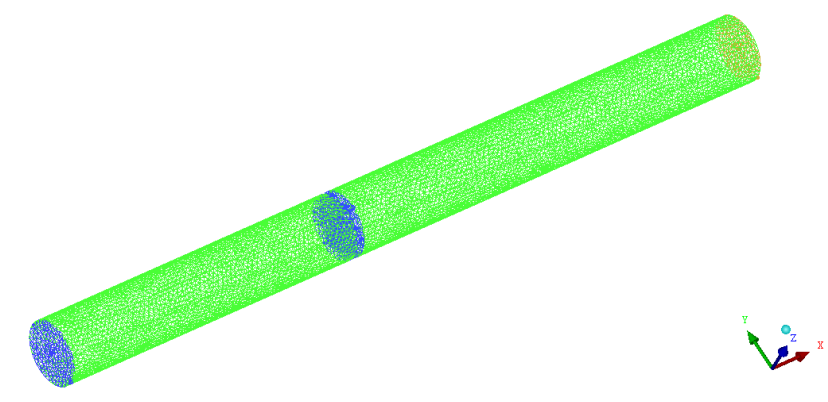

Figure 9: Mesh of Orifice Pipe

\section{B. INPUT DATA AND BOUNDARY CONDITIONS}

The domain is kept stationary and the fluid used was water. The k-epsilon model was used as the turbulent model velocity is given as inlet boundary condition, atmospheric pressure as outlet boundary condition and no slip wall is considered for wall boundary condition.

\section{EQUATIONS}

Theoretical discharge,

$$
Q_{t}=A * \beta^{2} *\left(\frac{2 * 9.81 * d H}{1-\beta^{4}}\right)^{0.5}
$$

Where,

$\beta=\sqrt{\frac{\text { total area of orifice Hole }}{\text { total area of pipe }}}$

Actual discharge,

$\mathrm{Q}_{\mathrm{a}}=\frac{\mathrm{Ar}}{\mathrm{t}}$

Coefficient of Discharge,

$\mathrm{C}_{\mathrm{d}}=\frac{\mathrm{Q}_{\mathrm{a}}}{\mathrm{Q}_{\mathrm{t}}}$

\section{Results \& Discussion}

Pressure and velocity have been computed by using CFD code for various orifice plates. The results and outcomes are presented in the form of pressure contour, velocity contours and graphs showing comparison of $\mathrm{C}_{\mathrm{d}}$.

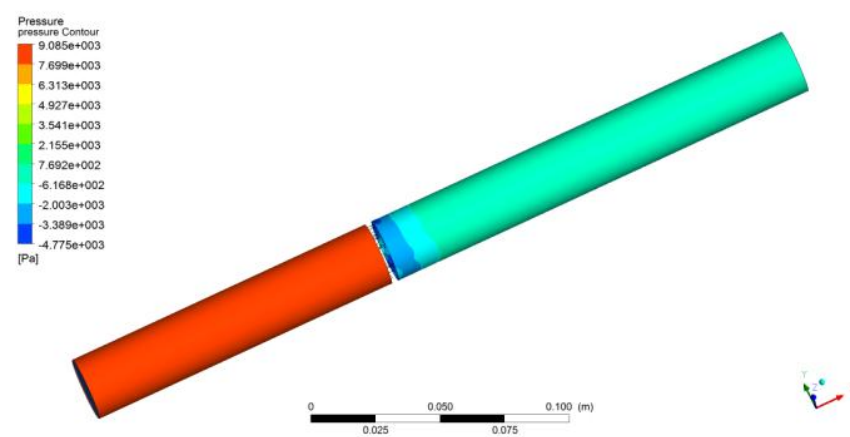

Figure 10: Pressure Contour for 7 Hole Orifice Plate

From pressure contour, pressure distribution in various regions can be seen. Pressure is maximum at inlet of pipe. Due to contraction and expansion of area in the orifice plate region, the pressure decreases and 
then gradually increases. So, it can be seen that there is difference in pressure between inlet \& outlet of pipe because some pressure losses in sections.

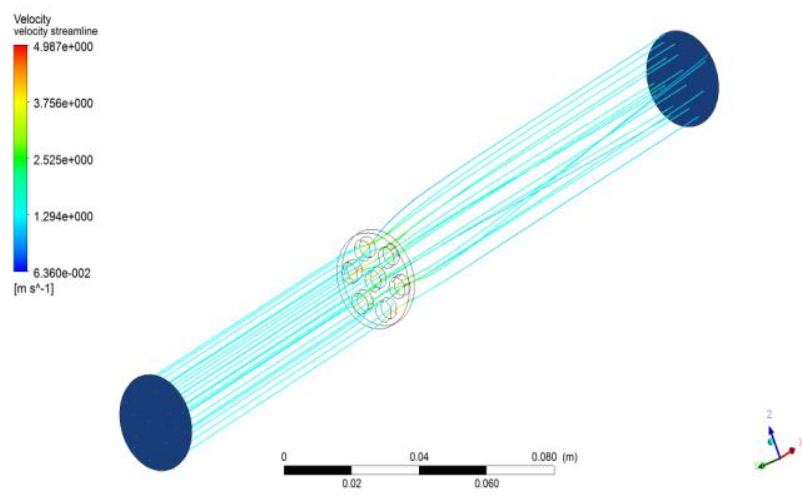

Figure 11: Velocity Streamline for 7 Hole Orifice Plate

From velocity streamlines, velocity distribution in various regions can be seen. Velocity is minimum at inlet of pipe which is shown by blue streamlines. As area decreases (orifice plate) gradually velocity increases. In downstream pipe, velocity is becomes constant due to constant area of pipe. The $\mathrm{C}_{\mathrm{d}}$ obtained for various plates are:

Table 1: Cd for Different Plates

\begin{tabular}{|l|l|l|}
\hline Sr. no. & Orifice Plate & $\mathbf{C}_{\mathbf{d}}$ \\
\hline 1 & Single Hole & 0.68 \\
\hline 2 & 5 Hole & 0.738 \\
\hline 3 & 7 Hole & 0.762 \\
\hline 4 & 9 Hole & 0.726 \\
\hline 5 & Triangular Hole & 0.695 \\
\hline
\end{tabular}

D. Comparison of $C_{d}$ for different plates

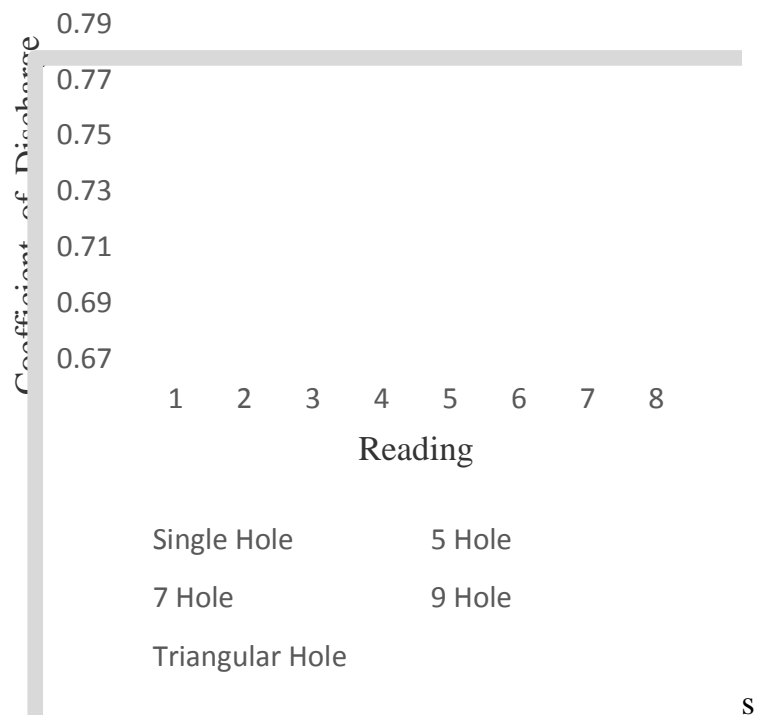

Graph 1: Comparison of Cd for Different Plates

The graph shows that the performance of perforated orifice plate is better than that of a single hole orifice plate. The $\mathrm{C}_{\mathrm{d}}$ of single hole orifice plate is least as compared to perforated and triangular hole orifice plate. The $C_{d}$ of 7 hole orifice plate is found to be maximum followed by 5 , 9, triangular and single hole respectively. The design of 7 hole orifice is such that there are less losses due to sudden contraction and expansion. The pressure drop in pipe with 7 hole orifice plate is lesser than in pipe with single, 5, 9, triangular hole orifice plate. Hence the $\mathrm{C}_{\mathrm{d}}$ of 7 hole orifice plate is highest. 
E. Comparison of CFD and Experimental $C_{d}$ for 7 Hole Orifice Plate

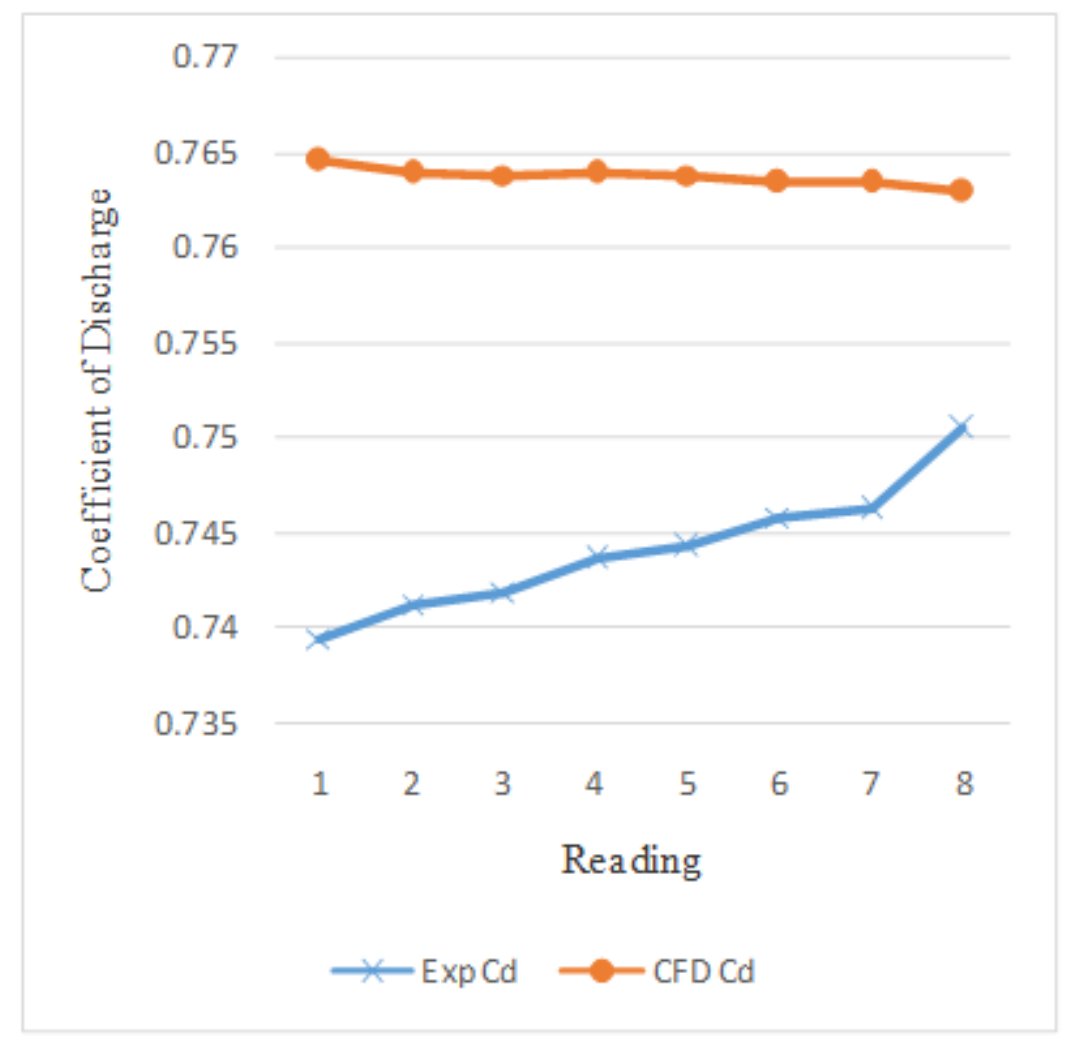

Graph 2: Comparison of CFD and Experimental Cd for 7 Hole Orifice Plate

The analysis is done to validate the CFD methodology by comparing the results with the experimental data. It can be seen that the $\mathrm{C}_{\mathrm{d}}$ found out from CFD is greater than that found from experimentation. This is because losses are not considered in CFD. The $\mathrm{C}_{\mathrm{d}}$ obtained through CFD simulations is $1 \%-4 \%$ greater than experimental $\mathrm{C}_{\mathrm{d}}$.

\section{Conclusion}

In this work, perforated orifices have been experimentally studied in terms of discharge coefficient and compared with a single hole orifice plate which is generally used in orifice meters to measure flow. The following points are obtained as the results of this study. Perforated orifice plate has better performance characteristics than a single hole orifice plate. Through simulation and experimentation, the 7 holes orifice plate is found to be having the highest value of coefficient of discharge i.e. 0.76 with an actual discharge of $3.82 * 10^{-4}$ $\mathrm{m}^{3} / \mathrm{s}$. Compared with single hole orifice plate, the coefficient of discharge of 7 holes orifice plate is $10-12 \%$ greater. The $\mathrm{C}_{\mathrm{d}}$ found out from CFD is greater than that found from experimentation because of the losses occurring in the physical model due to friction inside the pipe, leakage, impurities present in the fluid, etc. which are not considered in CFD.

\section{References}

[1]. Yogesh Kumar, G. S. Karthik, V. Seshadri, "A Modified Orifice Meter for Measuring Two Phase Flow," Journal of Hydraulic Research, pp. 161-187, Feb 2015.

[2]. Karthik G. S, Yogesh Kumar, V. Seshadri, "Prediction of Performance Characteristics of Orifice Plate Assembly for Non-Standard Condition using CFD," International Journal of Engineering and Technical Research (IJETR), vol. 3, no. 5, May 2015

[3]. Mohamed A. Siba, Wan Mohd Faizal Wan Mahmood, Mohd Z. Nuawi, Rasidi Rasani, Mohamed H. Nassir, , "Wall Pressure due to Turbulent Flow through Orifice Plate," International Journal of Mechanical and Mechatronics Engineering IJMME-IJENS, vol. 15, April 2015.

[4]. T. Sridevi, Dhana Sekhar, V. Subrahmanyam, "Comparison of Flow Analysis through a Different Geometry of Flowmeters using Fluent Software," International Journal of Research in Engineering and Technology (IJERT), vol. 3, no. 8, Aug 2014.

[5]. Malatesh Barki, Ganesha T, M. C. Math, "CFD Analysis and Comparison of Fluid Flow through a Single Hole and Multi Hole Orifice Plate," International Journal of Research in Advent Technology, Vol.2, No.8, Aug 2014.

[6]. F. Saltara, J. L. Baliño, "Investigation of Flow Upstream of Orifices," Journal of Hydraulic Engineering, ASCE, pp. 98-104.

[7]. $\quad$ F. H. J. Imada, F. SaltaraJ. L. Baliño, "Numerical Determination of Discharge Coefficients of Orifice Plates and Nozzles," International Congress of Mechanical Engineering, 3 Nov 2013.

[8]. W. Malalasekra, "Computational Fluid Dynamics (CFD) Analysis of Orifice Plate Metering Situations under Abnormal Configurations," NEL Technology for Life, Aberdeen, KEE012, May 2013. 